Peer-Reviewed Article
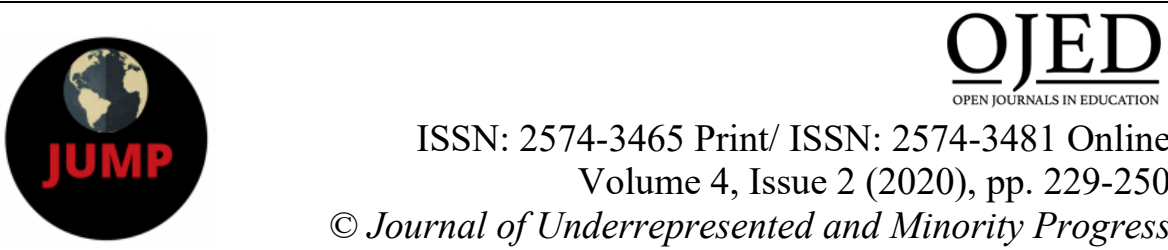

ISSN: 2574-3465 Print/ ISSN: 2574-3481 Online

Volume 4, Issue 2 (2020), pp. 229-250

(C) Journal of Underrepresented and Minority Progress

http://ojed.org/jump

\title{
Available but Not Approachable: Black Student Interactions with Business Faculty at a Historically White Institution
}

\author{
Monica E. Allen \\ North Carolina A\&T State University, USA \\ Sandra L. Dika \\ University of North Carolina at Charlotte, USA
}

\begin{abstract}
Persistent racial inequities in educational attainment and employment negatively affect the economic mobility of the Black population in the United States. Among college graduates, Black people are underrepresented in most high-paying college majors, except for business. In this phenomenological study framed by Critical Race Theory, Black business students (n=10) at a Historically White Institution shared their perceptions of the climate and experiences of interactions with faculty. Students reported they often felt unwelcome and othered in the White-dominated space and received limited support from White faculty that were frequently "available but not approachable". Future research and practice should focus on institutional strategies to address racism by developing an equitable and welcoming business school culture and fostering cultural competence of faculty.
\end{abstract}

Keywords: Academic persistence, Black/African American students, Critical Race Theory, student-faculty interactions 


\section{INTRODUCTION}

Inequitable access to and successful completion of college continue to be defining factors in the American racial economic divide. The majority of jobs in the American economy require postsecondary education or training (Carnevale, Jayasunde, et al., 2016), thus a college degree is vital for participation in the labor market and economic mobility. While degree attainment in the population rose from 2010 to 2019 for all racial and ethnic groups, Black attainment remained $14 \%$ behind non-Hispanic Whites (U.S. Census Bureau, 2020). Unemployment gaps persist for the Black population. Since the Bureau of Labor Statistics began collecting data in the early 1970s, the unemployment rate for Black Americans has consistently been twice the White unemployment rate (Ajilore, 2020), and unemployment rates are even higher for the Black population in Black-majority cities (Perry, 2019).

While several factors contribute to the disproportionate unemployment levels for Black Americans, two of the most prevalent are lower degree attainment and concentration of degree majors (Carnevale, Fasules, et al., 2016). Among adult degree holders (21-59 years old), the Black population is highly concentrated in lower-paying college majors and underrepresented in most high-paying majors, including science, technology, engineering, and mathematics (STEM) and the highest paying business majors (accounting, finance, marketing) (Carnevale, Fasules, et al., 2016). When looking only at recent degree completers rather than the adult population at large, the picture changes slightly. In 2016-17, the proportion of business degrees awarded to Black students (10\%) was near their proportion in the overall population (13\%) (National Center for Education Statistics, 2018). Business, management, and marketing were among a limited number of higher-paying fields in which Black students were as likely as White students to receive a degree between 2013 and 2015 (Libassi, 2018). These recent numbers offer tentative evidence of more equitable participation of the Black population in business fields.

While there is a significant body of research on the experiences of Black and other minoritized students in STEM majors due to their significant underrepresentation, there has been limited research examining the perceptions and experiences of Black students in business majors. Earlier evidence suggested that Black students in business were more likely to persist than their counterparts in majors with lower immediate economic returns such as the social sciences (St. John et al., 2004). Studies on Black students' choice of higher-paying business majors suggests the importance of exposure to those careers and majors. Black students who considered accounting or 
finance but ultimately chose other business majors indicated that their choice was based on career-centered factors: occupational growth, long-term salary prospects, and opportunities for ongoing professional development (Young et al., 2018). Further, they noted that the college website and the internet were their most important sources of information for major selection. Among Black accounting majors in another study, the introductory accounting course and knowing an accountant who served as a role model were important factors in their choice (Violette \& Cain, 2017). When considering interaction with faculty, Parks-Yancy (2012) found that the few low-income first-generation Black business students who interacted with professors or approached the career office received direction that helped them identify career opportunities they had not previously considered.

Higher education scholars have called for more deliberate attention to how race and racism affect the experiences of Black college students (Patton, 2016) and more aggressive efforts to address equity agendas in higher education (Museus et al., 2015). There is a need for continued research to understand Black students' interactions and experiences with predominantly White faculty (Erskine-Meusa, 2017), to generate evidence to improve the college climate for Black students leading to greater participation in higherpaying fields. The purpose of our phenomenological study was to understand how persisting Black business students at a Historically White Institution (HWI) in the southeast perceive the climate of the business school and their interactions with faculty. The study design was based on an understanding of existing literature about Black students' college experiences and interactions, specifically related to perceived climate and interactions with faculty, and viewed through the lens of Critical Race Theory (CRT).

\section{LITERATURE REVIEW}

Given the increasing participation of the Black population in business majors and the limited research on their experiences and interactions with faculty in those majors, we consulted a broader literature base to help contextualize our study. We reviewed the literature on Black student perceptions of institutional climate and interactions with faculty. These literature bases provide a background to understand the main concepts under exploration in our study and to relate to our findings to suggest implications for more equitable practice.

Positive campus climates (Hausmann et al., 2007; Museus et al., 2018) are associated with a greater sense of integration and student persistence (Tinto, 1993). Black students at HWIs often find themselves in negative racial climates characterized by stereotypes, prejudice, and 
discrimination (Nora \& Cabrera, 1996; Solórzano et al., 2000) which can lead to experiencing alienation, isolation, and reduced motivation (Charleston et al., 2014; Lancaster et al., 2017). Black students are not prepared for culture shock (Sinanan, 2012), and they may be singled out in the classroom, pressured to speak for all Black experiences, forced to prove their worthiness, exposed to insensitive attitudes, and be questioned about Black academic abilities (Davis et al., 2004).

Previous research has signaled the critical role of relationships with faculty in student enrollment and persistence (Li et al., 2009; Lundberg et al., 2018). Involvement with faculty leads to greater effort, enhanced learning, and academic success (Tinto, 2016). There is strong research support for the notion that student-faculty interactions are vital to enhancing student motivation and achievement (DeFreitas \& Bravo, 2012; Engstrom \& Tinto, 2008; Lundberg \& Schreiner, 2004; Roksa \& Whitley, 2017; Strayhorn, 2008). Positive interactions with faculty influence students' aspirations to achieve at a higher level, resulting in increased confidence in academic skills and enhancement of intellectual self-concept (Cole, 2007; DeFreitas \& Bravo, 2012; Grantham et al., 2015; Komarraju et al., 2010). Also, positive interactions enhance students' sense of belonging in the academic environment to embrace the idea that they can have a successful academic career (DeFreitas \& Bravo, 2012). In contrast, when students feel distant from faculty members, they experience a lack of motivation, discouragement, and a feeling of apathy (Komarraju et al., 2010).

For Black students, in particular, the perceived quality of the relationship and support from faculty have been linked to academic success (Anaya \& Cole, 2001; Charleston, 2012; Cole, 2008; Cole \& Espinoza, 2008; Roksa \& Whitley, 2017). Positive interactions can serve to increase selfconfidence and aspirations to achieve at higher levels (Komarraju et al., 2010; Roksa \& Whitley, 2017). While students desire to interact with faculty, research suggests that faculty may need to take the first step and reach out to Black students who may find it difficult to approach them, particularly when the faculty member is of a different race (Museus et al., 2008). At HWIs, Black students may be particularly influenced by interactions with faculty. Black students want to feel that they belong, that they are cared about, and they have allies to support them through their learning process (Lundberg \& Schreiner, 2004). They need faculty to be student-centered and culturally sensitive to their needs (Erskine-Meusa, 2017; Guiffrida, 2005; Miller \& Mills, 2019).

Satisfying and frequent relationships with faculty encourage students to work harder and provide an important foundation for student effort toward 
academic success (Cotton \& Wilson, 2006; Roksa \& Whitley, 2017). It is during these interactions, that faculty have "the opportunity to model the principles of equity, democracy, and respect" (Goodman, 2011, p. 179). Guiffrida (2005) noted that the African American tradition of "othermothering" was closely aligned with Black students' perceptions of valuable interactions with faculty: invest time and listen to the students; understand their career fears, dreams, and goals; provide academic and personal advising; support and advocate for the students; provide information and resources needed to navigate the institution; and most importantly, show that they care about students' success. In a recent study, Beasley (2020) found that a perceived caring attitude of faculty members was predictive of academic and social engagement for Black undergraduate students at a predominantly White institution. In a study of faculty attitudes and behaviors of thriving students of color, researchers found these faculty engaged learners where they are, connect personally with students in and out of class, embrace diverse learners, and see students as individuals (Vetter et al., 2019).

\section{CRITICAL RACE THEORY FRAMEWORK}

Higher education systems in the United States are "constructed and unequal hierarchies" (p. xvii) in which Black students experience differential access to power and privilege (Adams et al., 1997). While education is touted as the great equalizer, the net worth of White households is more than three times that of Black households with the same degree attainment (Darity, Jr. et al., 2018). Despite the development of multiple theories that provide explanations for student academic success in higher education, the framework of the majoritarian remains the norm. Attention to the concepts of race and racism in higher education is rarely the focal point in the analysis of academic success and achievement of Black students (Yosso et al., 2004). The need to examine institutional racism is vital for the transformation of the inequities in the higher educational system (Banks et al., 2020; Closson, 2010). We used the lens of Critical Race Theory (CRT) to frame our study of the experiences of Black business students because it acknowledges the importance of their counter-stories while persisting in a Historically White Institution.

CRT was born in the 1970s out of the work of Bell and several other legal scholars, who were reexamining the persistence of racism in America and the lack of racial reform in traditional civil rights legislation. The movement spread into other areas, including education (Hiraldo, 2010; Taylor, 1998), where research put race and racism at the center of scholarship and analysis while trying to understand how the dominant culture and its 
oppression of Black people had been established and perpetuated (Lynn \& Adams, 2002).

While CRT is not a set of rules or ideas, its scholarship is marked by specific themes (Taylor, 1998). Education scholars (Ladson-Billings, 1999; McCoy \& Rodricks, 2015; Yosso et al., 2004) have described six themes or tenets of CRT:

1) Racism is Permanent - CRT seeks to "unmask and expose" racism in America (Ladson-Billings, 1998). Racism is ingrained in American culture and appears to be normal and natural because American society expects everyone to conform to the norms of the White, Christian, middle-class, heterosexual dominant group.

2) Challenge to Dominant Ideology - CRT challenges White privilege and argues that concepts of objectivity, meritocracy, colorblindness, race neutrality, and equal opportunity act as a camouflage for the self-interest, power, and privilege of the dominant culture in America (McCoy \& Rodricks, 2015).

3) Centrality of Experiential Knowledge - CRT uses the counterstories of Blacks to understand their experiences, narratives, and histories and support the concept that their experience of oppression is legitimate, appropriate, and critical to understanding and analyzing their plight (Closson, 2010; Howard \& Navarro, 2016; Ladson-Billings, 1998; Yosso \& Solórzano, 2005).

4) Interest Convergence Theory - CRT posits that the interests of Blacks will only occur when there is a convergence with the interests of those in power and there is an elimination of racism, sexism, and the empowerment of Blacks (McCoy \& Rodricks, 2015; Yosso \& Solórzano, 2005).

5) Intersectionality - CRT contends that Blacks not only experience oppression because of their race but also because of other identities (gender, class, religion, ability/disability, sexual orientation, etc.) and forms of oppression (sexism, ableism, homophobia, etc.) (Ladson-Billings, 1999; McCoy \& Rodricks, 2015; Patton, 2016).

In the field of education, CRT scholars "theorized, examined, and challenged how race and racism shape schooling structures, practices and discourses" (Yosso et al., 2005, p. 3). In higher education, it has been an important tool used to broaden and deepen the analysis of the racialized 
barriers erected for people of color. Particularly, the use of CRT has informed educators in the effort to identify and challenge macro- and microaggressions experienced by Black students on campuses across the country (Solórzano et al., 2005). Centrality of Experiential Knowledge (Closson, 2010; LadsonBillings, 1998; Yosso \& Solórzano, 2005), focused on the counter-narratives of Black students, is the tenet most aligned with the purpose of our study, and further guided the choices of the study's methodology.

\section{RESEARCH METHODS}

Our purpose for this study was to understand the educational experiences of Black business students at an HWI in the southeastern United States, related to their perceptions of the climate of the College of Business and their interactions with business faculty. Specifically, we sought to explore the phenomenon of persistence in an HWI business school through a CRT lens. We used phenomenological interviews as the primary data source, which allowed us to capture the experiential knowledge of the students (Merriam \& Tisdale, 2016; Ravitch \& Carl, 2016).

\section{Setting and Participants}

The setting for this study was an urban research university located in a large southeastern U.S. city, where the population is $36 \%$ Black (U.S. Census Bureau, 2018), yet only $17 \%$ of all students, and $14 \%$ of business students identified as Black/African American. Participants in the study were junior or senior business students who self-identified as Black/African American, 18-24 years old, attending school full-time, and maintaining a Caverage or higher in coursework. Students meeting these criteria were first identified by the Dean's office and affinity groups then were invited via email or in person by the first author. In total, 10 students agreed to participate and were interviewed. In Table 1, demographic details about each participant are shown, along with an identifying code for their quotes in the study findings. Participants ( 8 women, 2 men) were enrolled in varied business degree programs, the most common being management $(n=4)$ and marketing $(n=4)$. Four of the students identified as being first-generation students, and five were transfer students. While first-generation and transfer status are both related to persistence in higher education, they are included here for purposes of demographic description. Student experiences related to these statuses are not explicitly explored in this study. 


\section{Table 1}

Demographic Characteristics of Participants $(\mathrm{n}=10)$

\begin{tabular}{llllcc}
\hline Identifier & Gender & Class & \multicolumn{1}{c}{ Major } & Transfer & $\begin{array}{c}\text { First- } \\
\text { Generation }\end{array}$ \\
\hline F1 & Female & Senior & Finance & $\mathrm{X}$ & \\
F2 & Female & Junior & Management & & $\mathrm{X}$ \\
M1 & Male & Senior & Marketing & & $\mathrm{X}$ \\
F3 & Female & Junior & Marketing & $\mathrm{X}$ & $\mathrm{X}$ \\
F4 & Female & Junior & Management & $\mathrm{X}$ & \\
F5 & Female & Senior & International & & \\
& & & Business & & \\
M2 & Male & Junior & Management & $\mathrm{X}$ & \\
F6 & Female & Senior & Management & $\mathrm{X}$ & \\
F7 & Female & Senior & Marketing & & $\mathrm{X}$ \\
F8 & Female & Senior & Marketing & & \\
\hline
\end{tabular}

\section{Data Collection and Analysis}

After providing consent online to participate, students completed a short online demographic survey and set up an appointment for an interview. The semi-structured interview protocol (Appendix A) included questions to elicit student perceptions of the climate and culture of the college, relationships and interactions with faculty, and their understanding of the role of their race in their experiences. Interviews conducted face-to-face by the first author (a Black woman), ranged between 60 to 90 minutes, and provided the students an opportunity to share the stories of their lived experiences (Merriam, 2009; Roulston, 2010; Strauss \& Corbin, 1988). During the interviews, several of the participants became very emotional and overcome with tears. Interviews were digitally recorded and transcribed verbatim.

First, we listened to the interviews while reviewing the transcripts to become familiar with the data and with each participant. Then, the first author took the lead in the data analysis. Broad a priori categories combined with open descriptive coding (Saldaña, 2016) were used to code the transcripts. Memoing was used to note analytical thoughts about the significance of and the relationship between codes, noting the connections to the CRT tenet of Centrality of Experiential Knowledge. The use of reflexivity provided an opportunity to (a) address any problems that are not easily explained; (b) include descriptive and other relevant statements that would help others understand the study and its final report; (c) address the dependability and confirmability of the data. After reviewing the codes, we debriefed to 
compare notes and group the codes into categories and cross-cutting themes (Appendix B). The final step included identifying key quotations.

\section{Author Positionality Statement}

The research team includes individuals with different levels of personal experience and research expertise related to the focus and purpose of this study. Allen identifies as a Black woman, and she has personal experience as both a business student and a faculty member (not at the study institution). She conducted interviews with students and had primary responsibility for data analysis. Dika identifies as a White woman, and she contributed expertise in educational research design and scholarly focus on students of color and other marginalized groups in higher education. We are committed to conducting research that leads to more inclusive and equitable policies and practices to promote the greater attainment of Black students and other minoritized groups, which guided the selection of the CRT lens and qualitative research methodology.

\section{FINDINGS}

We identified two themes related to the experiences of Black business students at an HWI: (a) an unwelcoming climate; and (b) faculty as available, but not always approachable.

\section{An Unwelcoming Climate}

Institutions of higher education expect Black students to assimilate into the culture of the university. The students we interviewed did not find assimilation to be an easy feat. The competitive, challenging, professional, and rigorous climate of the college left the participants feeling overwhelmed, intimidated, and extremely stressed.

I think the business college is very competitive... I'd say the climate is very different from other colleges on campus... when I walk into this building, I just feel like oh, somebody's watching me...it's very intimidating because you do see a lot of the majorities around more than the minorities. (M2)

They believed that the college's strict policies, procedures, and requirements reinforced a competitive environment aimed to weed out students. One female junior student spoke at length about this. 
Accounting... that's the biggest weed out course for a lot of business students...a lot of people switch their major because they can't pass that....my Econ teacher was basically like, 'hey, just to let you know, you all are not going to make it... you're going to be broke, and you're going to have 10 different jobs, so just get used to it right now'... it was almost very intimidating...I think because I feel like people would assume that, because I'm Black, that I would do like psychology or an easier major. (F2)

The students described the climate as one filled with microaggressions, stereotypes, and prejudice, which reminded the students that they were different due to their race. This resulted in the students questioning their academic abilities.

I just didn't feel like it is very inviting. I just didn't feel like it was very inclusive.... I kind of wish I did see more African American people in my program because it wouldn't be as uncomfortable. I think it's that whole psychological aspect of when you recognize or see other people of your race, it makes you a little bit more at ease. (F5)

Throughout my experiences, there were times when I just didn't understand the material. Even though I wanted to go to the professor for help, I was afraid. I felt he made pre-judgments about me. (M1)

I've had an interaction with a teacher who was just very demeaning. You could ask a question...he would chastise you for asking him a question. It really made it hard for me to want to go to that class and deal with that for an hour and 15 minutes. He just made me question my intelligence. I know I'm not dumb. (F1)

Constant reminders of being "other" or "outsider" made navigating the college and the university challenging. The students sometimes found it difficult to keep motivated and persist toward degree completion.

The unwelcoming climate in the business college manifested itself as being exclusive and White-centric. Students reported challenges to assimilation, the threat of being "weeded out" (eliminated), and feelings of being an imposter or outsider. The students referenced climate as policies and procedures, as well as perceptions about the classroom environment and 
relationships with other students. Students' descriptions of interactions with faculty offered further insight into their experiences in the business college.

\section{Business Faculty Can Be Available, But Not Always Approachable}

Looking for guidance and knowledge, students interacted daily with faculty members. Although available during class and office hours, many faculty members did not seem approachable. Those deemed unapproachable were perceived as not being inviting or genuinely interested in assisting the students through both verbal and nonverbal cues.

Students looked for cues to determine if a faculty member was welcoming, open to engaging, and committed to helping the students succeed. They paid close attention to what was communicated, how it was communicated, body language, and responsiveness to questions. The interpretation of these cues had a direct impact on whether or not the students approached the faculty member.

The way they walk into the classroom and present the material has influence on how well I can do in that class. Unfortunately, I feel like the majority of my interactions are the same...just because of their attitudes when they're in class...it makes me feel a little uncomfortable. (F4)

I do go to office hours to get extra help...I don't get my hopes up. I go just to exhaust all my chances. I'm not really confident, when I go to office hours, that my question will be answered or my problem will get solved. (F5)

I do feel comfortable going to get the extra help...I [just] don't get my hopes up...once [a professor] kept giving me signals that he was not interested in what I was asking. He continually checked his watch and asked 'So did you just want to look over your test? What did you need?" I wanted to look over the test to better prepare for the next test... he said 'I don't know what you don't get. It's simple, it's not rocket science' ... at that point I didn't ask any more questions and left upset. (F8)

There was one Black faculty member in the college, a man, who students described as approachable and relatable, as more genuine and engaging. Interactions with this professor left the students feeling encouraged, confident, and focused on their success. 
When one can't relate to the faculty, you don't know what to talk about. Some things become easier when you have someone who is relatable. You can just talk about anything with them. (M1)

I feel like I automatically let my guard down when I'm talking to [him]. It felt more comfortable...He loves to talk about his family and class...[he] will tell stories in class and connect everything back to what we are learning...[he] knows me...I have the best relationship with him. (F7)

Immediately, I had a level of comfort. When I was in class, the professor pushed us to do our best. Although I am no longer in that class, I sent the professor an email, earlier this semester...[he] responded 'feel free to stop by my hours. Anything you need, I'll help you.' The professor always made me feel encouraged. (F1)

I felt very comfortable just speaking with the professor about things that were going on in my personal life or with school. (F5)

Student participants expressed that they needed faculty to be welcoming, encouraging, open to approaching students, and willing to get to know the students. Further, they wanted faculty to be aware of the challenges Black students face, understand cultural differences, and support their academic needs.

The notion of faculty approachability was described by the students as both verbal and nonverbal cues they picked up on in the classroom and when they went to visit faculty during office hours. They felt academic support from the lone Black faculty member and the importance of his presence in the college was made apparent by all participants. Their expressed needs for faculty interaction and support were clearly in contrast to their overall experiences.

\section{DISCUSSION AND IMPLICATIONS}

We designed this study to gain an understanding of how successful Black business students perceived their interactions with faculty related to their academic persistence. Using CRT as a framework, we gained insight as to the perceived pressures associated with being a Black student and the role faculty played in the learning experience. Supported by the CRT tenet of 
Centrality of Experiential Knowledge, the counter-stories of the students provided an opportunity for us to recognize their experiences of oppression.

Within the field of higher education, researchers have increasingly used CRT as an important tool used to broaden and deepen the analysis of the racialized barriers for people of color (Solórzano et al., 2005). Scholars of CRT have concluded that the needed attention to the concepts of race and racism in higher education is rarely the focal point of the analysis of academic success and achievement of students of color. Although race has been mostly used as a demographic variable, there was a need for an explicit focus on racism to transform the inequities found in the U.S. higher educational system (Closson, 2010).

Our findings indicated that the students perceived a competitive and unwelcoming environment, which in turn caused them to feel overwhelmed, intimidated, isolated, and stressed (Keels et al., 2017). Although this may be common among business students, the racially charged climate had an even greater effect. The students described a culture riddled with stereotypes and prejudices that left them struggling to feel integrated and motivated to persist (Fries-Britt \& Turner, 2002). Although they successfully continued through their studies, the students had many peers who decided to give up and left the college, and in some cases, the university (Fries-Britt \& Turner, 2002). As a result of experiences of discrimination and microaggressions, the students suffered from increased stress and pressures that affected their academic performance (Cabrera et al., 1999).

Once on campus, the students in our study indicated that they were expected to break away from the cultural conditioning of home and assimilate into the culture of the university and the business college (Banks et al., 2020). They did not find it easy to assimilate into the dominant culture of the college, based on the constant reminder that they were different or an outsider (Cress, 2008). Their experiences resulted in dissatisfaction with the racial climate in the college (Banks et al., 2020; Banks \& Landau, 2019; Solórzano et al., 2000). The students found themselves in an environment where the majority of the faculty and peers were White. Although faculty were valued as a resource needed to instill knowledge and provide support, these Black students felt that the faculty treated them differently than their White peers. Daily, the students had contact with faculty members in the classroom. They often did not approach faculty because of the perceptions of potential prejudgments about Black students. Supporting these findings, previous research found that when faculty interactions appeared to be inviting and rewarding, there was a strong association with continued student academic success 
(Anaya \& Cole, 2001; Cole, 2008; Cole \& Espinoza, 2008; Li et al., 2009; Tinto, 1987, 1993).

An important finding in this study was that students picked up on verbal and non-verbal cues from faculty to determine if the faculty member was welcoming, committed to student success, and willing to help the students succeed (Beasley, 2020). These cues were associated with how the faculty member talked to the students, their body language, and their responsiveness to questions. When the cues were positive, the students did not hesitate to approach the faculty member for assistance (Burrell et al., 2015). In contrast when the cues were negative (e.g., microaggressions), they were hesitant to approach. Not being able to take full advantage of the faculty member's guidance, some students experienced a negative impact on their academic experience. The students appreciated the positive cues they received from the lone Black faculty member in the college. They found him to be more relatable, showing a better understanding of their social, educational, and personal needs (Guiffrida, 2005). As a result, these interactions seemed more genuine, engaging, easier, and comfortable, which resulted in a positive impact.

\section{IMPLICATIONS FOR RESEARCH}

Limitations and delimitations of the current study suggest directions for future research. During the interview process, we noted that students lacked clarity on the meaning of the word "culture". As a result, the students provided more insight into their perceptions of the climate versus the culture of the College of Business. In future studies, researchers could employ ethnographic methods including observation and document analysis to provide a more comprehensive understanding of program culture and student behaviors and experiences within that culture.

Students noted the business college's climate as being structured, challenging, professional, and rigorous. Therefore, different methodologies or other theoretical frameworks that explicitly examine culture could be employed to more deeply understand how Black students experience business programs at HWIs. Future studies could also include Black students in other competitive majors (health, engineering) to understand how perceptions and experiences are similar and different.

The perception of business faculty as unapproachable among students in the current study also suggests directions for future research. Future studies could include faculty perspectives as well as observation of student-faculty interaction in and out of class to develop a more nuanced understanding of the notion of approachability. Perspectives of White faculty and faculty of color about their interactions with Black business students would further 
explore how faculty perceive and interact with students, and how those interactions are in turn perceived by the students.

Finally, the overarching theme of being perceived as the other among Black students in business majors and careers is certainly worthy of additional exploration, particularly related to CRT and other critical theories.

\section{IMPLICATIONS FOR PRACTICE}

The findings of this study reinforce that colleges of business must pay attention to creating positive and equitable experiences and environments for Black students. We offer two suggestions to improve climate and studentfaculty relations for Black and other under-represented students. First, to play an active role in creating a positive college climate, faculty need to learn more about their biases, cultural worldviews, and attitudes towards cultural differences. Cultural competency training would allow faculty to develop awareness and identify ways to help Black students connect with various segments of the institution (Davis et al., 2004). Design and implementation of a training program, aligned with the institution's mission, could be a collaborative effort of institutional offices (equity and inclusion; teaching and learning) and address microaggressions, systemic oppression, implicit bias, and racial identity development. Second, students would benefit from partnerships with local professionals and alumni for career preparation as part of a mentorship program. Racial diversity among the mentors would provide added benefits for minoritized students and would help facilitate holistic mentoring that goes beyond academics to include the curiosity and concern for students' cultural backgrounds and other social identities (Reddick \& Pritchett, 2015; Robnett et al., 2019). Relationships with successful professionals who look like them would provide Black students an opportunity to learn how to navigate in a business world full of race-neutral practices, policies, and patterns of racial inequalities.

\section{CONCLUSIONS}

The findings of this study contribute to the research surrounding the academic persistence of Black students, by focusing on the perceptions of an understudied group (business majors) using a Critical Race Theory lens. Black degree attainment remains behind non-Hispanic Whites, with significant underrepresentation in most high-paying majors leading to occupational and income disparities. Supportive structures and relationships with faculty are vital for the persistence of Black students on historically White campuses in historically White-dominated majors. The Black business students in our study noted how their experiences and interactions left them 
feeling unwelcome and othered, yet they persisted in an environment not designed for them. Rather than a deficit view of students, "...it is time to rethink higher education's approach to addressing racial inequities and adopt a more holistic and aggressive strategy to advance equity agendas" (Museus et al., 2015, p. 73). Interest Convergence Theory (McCoy \& Rodricks, 2015; Yosso \& Solórzano, 2005) suggests that if institutional agents are truly committed to achieving the outcomes they desire, they must embrace equity and inclusion more consciously and engage in intentional long-term efforts to achieve racial equity. Those efforts must include plans for hiring and retention of Black and other faculty of color in fields where they are underrepresented, along with cultural competency training for all faculty members to make an impact on institutional culture and climate.

\section{REFERENCES}

Adams, M., Bell, L. A., \& Griffin, P. (1997). Teaching for diversity and social justice: A sourcebook. Routledge.

Ajilore, O. (2020, February 24). On the persistence of the Black-White unemployment gap. Center for American Progress.

https://www.americanprogress.org/issues/economy/ reports/2020/02/24/480743/persistence-black-white-unemployment-gap/

Anaya, G., \& Cole, D. G. (2001). Latina/o student achievement: Exploring the influence of student-faculty interactions on college grades. Journal of College Student Development, 42(1), 3-14.

Banks, B. M., Adams, D. F., Williams, C., \& Piña, D. (2020). Preliminary investigation of efforts to improve awareness of racial microaggressions on campus. Journal of Underrepresented and Minority Progress, 4(1), 20-43.

Banks, B. M., \& Landau, S. E. (2019). Offensive or not? Examining the impact of racial microaggressions. Journal of Underrepresented and Minority Progress, 3(2), 51-65.

Beasley, S. T. (2020). Student-faculty interactions and psychosociocultural influences as predictors of engagement among Black college students. Journal of Diversity in Higher Education. Advance online publication. https://doi.org/10.1037/dhe0000169

Burrell, J. O., Fleming, L., Fredericks, A. C., \& Moore, I. (2015). Domestic and international student matters: The college experiences of Black males majoring in engineering at an HBCU. The Journal of Negro Education, 84(1), 40-55. https://doi.org/10.7709/jnegroeducation.84.1.040

Cabrera, A. F., Nora, A., Terenzini, P. T., Pascarella, E., \& Hagedorn, L. S. (1999). Campus racial climate and the adjustment of students to college: A comparison between White students and African-American students. Journal of Higher Education, 70(2), 134-60.

https://doi.org/10.1080/00221546.1999.11780759 
Carnevale, A. P., Fasules, M. L., Porter, A., \& Landis-Santos, J. (2016). African Americans: College majors and earnings. Policy Report. Center on Education and the Workforce: Georgetown University.

Carnevale, A. P., Jayasundera, T., \& Gulish, A. (2016). America's divided recovery: College haves and have-nots. Policy Report. Center on Education and the Workforce: Georgetown University.

Charleston, L. J. (2012). A qualitative investigation of African Americans' decision to pursue computing science degrees: Implications for cultivating career choice and aspiration. Journal of Diversity in Higher Education, 5(4), 222243. https://doi.org/10.1037/a0028918

Charleston, L. J., George, P. L., Jackson, J. F. L., Berhanu, J., \& Amechi, M. H. (2014). Navigating underrepresented STEM spaces: Experiences of Black women in U.S. computing science higher education programs who actualize success. Journal of Diversity in Higher Education, 7(3), 166-176. https://doi.org/10.1037/a0036632

Closson, R. B. (2010). Critical race theory and adult education. Adult Education Quarterly, 60(3), 261-283. https://doi.org/10.1177/0741713609358445

Cole, D. (2007). Do interracial interactions matter? An examination of student-faculty contact and intellectual self-concept. Journal of Higher Education, 78(3), 249-281. https://doi.org/10.1080/00221546.2007.11772316

Cole, D. (2008). Constructive criticism: The role of student-faculty interactions on African American and Hispanic students' educational gains. Journal of College Student Development, 49(6), 587-605.

https://doi.org/10.1353/csd.0.0040

Cole, D., \& Espinoza, A. (2008). Examining the academic success of Latino students in science technology engineering and mathematics (STEM) majors. Journal of College Student Development, 49(4), 285-300. https://doi.org/10.1353/csd.0.0018

Cotton, S. R., \& Wilson, B. (2006). Student-faculty interactions: Dynamics and determinants. Higher Education, 51, 487-519. https://doi.org/10.1007/s10734-004-1705-4

Cress, C. M. (2008). Creating inclusive learning communities: the role of studentfaculty relationships in mitigating negative campus climate. Learning Inquiry, 2(2), 95-111. https://doi.org/10.1007/s11519-008-0028-2

Darity, W., Jr., Hamilton, D., Paul, M., Aja, A., Price, A., Moore, A., \& Chiopris, C. (2018). What we get wrong about closing the racial wealth gap. Samuel DuBois Cook Center on Social Equity and Insight Center for Community Economic Development. https://socialequity.duke.edu/portfolio-item/whatwe-get-wrong-about-closing-the-racial-wealth-gap/

Davis, M., Dias-Bowie, Y., Greenberg, K., Klukken, G., Pollio, H. R., Thomas, S. P., \& Thompson, C. L. (2004). "A fly in the buttermilk": Descriptions of university life by successful Black undergraduate students at a predominately White southeastern university. Journal of Higher Education, 75(4), 420. https://doi.org/10.1080/00221546.2004.11772266 
DeFreitas, S. C., \& Bravo, A. J. (2012). The influence of involvement with faculty and mentoring on the self-efficacy and academic achievement of African American and Latino college students. Journal of the Scholarship of Teaching and Learning, 12(4), 1-11.

Engstrom, C. \& Tinto, V. (2008). Access without support is not opportunity. Change: The Magazine of Higher Learning, 40, 46-50. https://doi.org/10.3200/chng.40.1.46-50

Erskine-Meusa, D. (2017). African American students in the community college classroom with White teachers. Journal of Underrepresented and Minority Progress, 1, 66-79. https://doi.org/10.32674/jump.v1i1.37

Fries-Britt, S. L., \& Turner, B. (2002). Uneven stories: Successful Black collegians at a Black and a White campus. Review of Higher Education, 25(3), 315-30. https://doi.org/10.1353/rhe.2002.0012

Goodman, D. J. (2011). Promoting diversity and social justice: Educating people from privileged groups. Routledge.

Grantham, A., Robinson, E. E., \& Chapman, D. (2015). "That truly meant a lot to me": A qualitative examination of meaningful faculty-student interactions. College Teaching, 63(3), 125-132. https://doi.org/10.1080/87567555.2014.985285

Guiffrida, D. (2005). Othermothering as a framework for understanding African American students' definitions of student-centered faculty. The Journal of Higher Education, 76(6), 701-723. https://doi.org/10.1080/00221546.2005.11772305

Hausmann, L. R. M., Schofield, J. W., \& Woods, R. L. (2007). Sense of belonging as a predictor of intentions to persist among African American and White firstyear college students. Research in Higher Education, 48(7), 803-839. https://doi.org/10.1007/s11162-007-9052-9

Hiraldo, P. (2010). The role of critical race theory in higher education. The Vermont Connection. 31, 54-59.

Howard, T. C., \& Navarro, O. (2016). Critical race theory 20 years later: Where do we go from here? Urban Education, 51(3), 253-273. https://doi.org/10.1177/0042085915622541

Keels, M., Durkee, M., \& Hope, E. (2017). The psychological and academic costs of school-based racial and ethnic microaggressions. American Educational Research Journal, 54(6), 1316-1344. https://doi.org/10.3102/0002831217722120

Komarraju, M., Musulkin, S., \& Bhattacharya, G. (2010). Role of student-faculty interactions in developing college students' academic self-concept, motivation, and achievement. Journal of College Student Development, 51, 3, 332-342. https://doi.org/10.1353/csd.0.0137

Ladson-Billings, G. (1998). Just what is critical race theory and what's it doing in a nice field like education? Qualitative Studies in Education, 11, 7-25. 
Ladson-Billings, G. (1999). Preparing teachers for diverse student populations: A critical race theory perspective. Review of Research in Education, 24, 211 247. https://doi.org/10.2307/1167271

Lancaster, C., \& Xu, Y. J. (2017). Challenges and supports for African American STEM student persistence: A case study at a racially diverse four-year institution. The Journal of Negro Education, 86(2), 176-189. https://doi.org/10.7709/jnegroeducation.86.2.0176

Li, Q., Swaminathan, H., \& Tang, J. (2009). Development of a classification system for engineering student characteristics affecting college enrollment and retention. Journal of Engineering Education, 98(4), 361-376. https://doi.org/10.1002/j.2168-9830.2009.tb01033.x

Libassi, C. J. (2018, May 23). The neglected college race gap: Racial disparities among college completers. Center for American Progress.

https://www.americanprogress.org/issues/education-postsecondaryreports/ 2018/05/23/451186/neglected-college-race-gap-racial-disparities-amongcollege-completers/

Lundberg, C., Kim, Y., Andrade, L., \& Bahner, D. (2018). High expectations, strong support: Faculty behaviors predicting Latina/o community college student learning. Journal of College Student Development, 59(1), 55-70. https://doi.org/10.1353/csd.2018.0004

Lundberg, C. A., \& Schreiner, L. A. (2004). Quality and frequency of faculty-student interaction as predictors of learning: An analysis by student race/ethnicity. Journal of College Student Development, 45(5), 549-565. https://doi.org/10.1353/csd.2004.0061

Lynn, M., \& Adams, M. (2002). Introductory overview to the special issue critical race theory and education: Recent developments in the field. Equity \& Excellence in Education, 35(2), 87-92. https://doi.org/10.1080/713845285

Merriam, S. B. (2009). Qualitative research: A guide to design and implementation. John Wiley \& Sons.

Merriam, S. B. \& Tisdale, E. J. (2016). Qualitative research: A guide to design and implementation. Jossey-Bass.

Miller, A. C., \& Mills, B. (2019). "If they don't care, I don't care": Millennial and generation $\mathrm{Z}$ students and the impact of faculty caring. Journal of the Scholarship of Teaching and Learning, 19(4), 78-89.

McCoy, D. L., \& Rodricks, D. J. (2015). Critical race theory in higher education: 20 years of theoretical and research innovations. ASHE Higher Education Report, 41(3), 1-117. https://doi.org/10.1002/aehe.20021

Museus, S. D., Ledesma, M. C., \& Parker, T. L. (2015). Racism and racial equity in higher education. ASHE Higher Education Report, 42, 1-112. https://doi.org/10.1002/aehe.20067

Museus, S. D., Nichols, A. H., \& Lambert, A. D. (2008). Racial differences in the effects of campus racial climate on degree completion: A structural equation model. Review of Higher Education, 32, 107-134.

https://doi.org/10.1353/rhe.0.0030 
Museus, S. D., Yi, V., \& Saelua, N. (2018). How culturally engaging campus environments influence sense of belonging in college: An examination of differences between White students and students of color. Journal of Diversity in Higher Education, 11(4), 467-483. https://doi.org/10.1037/dhe0000069

Nora, A., \& Cabrera, A. F. (1996). The role of perceptions of prejudice and discrimination on the adjustment of minority students to college. The Journal of Higher Education, 67, 119-148. https://doi.org/10.2307/2943977

National Center for Education Statistics (2018). Bachelor's degrees conferred to males by postsecondary institutions, by racelethnicity and field of study: 2015-16 and 2016-17.

https://nces.ed.gov/programs/digest/d18/tables/dt18_322.40.asp

Parks-Yancy, R. (2012). Interactions into opportunities: Career management for lowincome, first-generation African American college students. Journal of College Student Development, 53(4), 510-523. https://doi.org/10.1353/csd.2012.0052

Patton, L. D. (2016). Disrupting postsecondary prose: Toward a critical race theory of higher education. Urban Education, 51(3), 315-342. https://doi.org/10.1177/0042085915602542

Perry, A. M. (2019, June 26). Black workers are being left behind by full employment. Brookings Institution. https://www.brookings.edu/blog/the-avenue/2019/06/26/black-workersare-being-left-behind-by-full-employment/

Ravitch, S. M. \& Carl, N. M. (2016). Qualitative research: Bridging the conceptual, theoretical, and methodological. Sage.

Reddick, R. J., \& Pritchett, K. O. (2015). I don't want to work in a world of "Whiteness": White faculty and their mentoring relationships with Black students. Journal of the Professoriate, 8(1), 54-84. https://caarpweb.org/jotp-spring-2015/

Robnett, R. D., Nelson, P. A., Zurbriggen, E. L., Crosby, F. J., \& Chemers, M. M. (2019). The form and function of STEM research mentoring: A mixedmethods analysis focusing on ethnically diverse undergraduates and their mentors. Emerging Adulthood, 7(3), 180-193. https://doi.org/10.1177/2167696818758734

Roksa, J., \& Whitley, S. E. (2017). Fostering academic success of first-year students: Exploring the roles of motivation, race, and faculty. Journal of College Student Development, 58(3), 333-348. https://doi.org/10.1353/csd.2017.0026

Roulston, K. (2010). Reflective interviewing: A guide to theory \& practice. Sage.

Saldaña, J. (2016). The coding manual for qualitative researchers (3rd ed.). Sage.

Sinanan, A. N. (2012). Still here: African American male perceptions of social and academic engagement at a 4-year, predominantly White institution of higher learning in southern New Jersey. SAGE Open, 2(2), 1-7.

https://doi.org/10.1177/2158244012445212 
Solórzano, D., Ceja, M., \& Yosso, T. (2000). Critical race theory, racial microaggressions, and campus racial climate: The experiences of African American college students. Journal of Negro Education, 69, 60-73.

Solórzano, D. G., Villalpando, O., \& Oseguera, L. (2005). Educational inequities and Latina/o undergraduate students in the United States: A critical race analysis of their educational progress. Journal of Hispanic Higher Education, 4(3), 272-294. https://doi.org/10.1177/1538192705276550

St. John, E. P., Hu, S., Simmons, A., Carter, D. F., \& Weber, J. (2004). What difference does a major make? The influence of college major field on persistence by African American and White students. Research in Higher Education, 45(8), 209-232. https://doi.org/10.1023/b:rihe.0000019587.46953.9d

Strauss, A., \& Corbin, J. (1998). Basics of qualitative research (2nd ed.). Sage.

Strayhorn, T. L. (2008). The role of supportive relationships in facilitating African American males' success in college. Journal of Student Affairs Research and Practice, 45, 26-48. https://doi.org/10.2202/1949-6605.1906

Taylor, E. (1998). A primer on critical race theory: Who are the critical race theorists and what are they saying? The Journal of Blacks in Higher Education, 19, 122-124.

Tinto, V. (1987). Leaving college: Rethinking the causes and cures of student attrition ( $2^{\text {nd }}$ ed,). University of Chicago Press.

Tinto, V. (1993). Taking student retention seriously: Rethinking the first year of college. National Academic Advising Association Journal, 19(2), 5-9. https://doi.org/10.12930/0271-9517-19.2.5

Tinto, V. (2016, September 26). How to improve student persistence and completion. Inside HigherEd Online. https://www.insidehighered.com

U.S. Census Bureau. (2018). Table S1701. Poverty status in the past 12 months. https://data.census.gov/cedsci/

U.S. Census Bureau. (2020, March 30). U.S. Census Bureau releases new educational attainment data.

https://www.census.gov/newsroom/press-releases/2020/educationalattainment.html

Vetter, M., Schreiner, L., \& Jaworski, B. (2019). Faculty attitudes and behaviors that contribute to thriving in first-year students of color. Journal of the FirstYear Experience \& Students in Transition, 31(1), 9-28.

Violette, G., \& Cain, C. L. (2017). Why are African American students still not majoring in accounting? The importance of early impressions. The CPA Journal, 87(12), 46-49.

Yosso, T. J., Parker, L., Solorzano, D. G., Lynn, M. (2004). From Jim Crow to affirmative action and back again: A critical race discussion of racialized rationales and access to higher education. Review of Research in Education, 28, 1-26. https://doi.org/10.3102/0091732x028001001 
Yosso, T. J., \& Solórzano, D. G. (2005). Conceptualizing a critical race theory in sociology. The Blackwell Companion to Social Inequalities. Blackwell. https://doi.org/10.1002/9780470996973.ch7

Young, J., Herath, S. K., \& McCoy, R. M. (2018). Why not accounting and finance: An African American perspective. Journal of Education for Business, 93(4), 165-171. https://doi.org/10.1080/08832323.2018.1437532

MONICA E. ALLEN, Ed.D., is an Assistant Professor of Leadership Studies in the Department of Leadership Studies and Adult Education at North Carolina A\&T State University. Her research agenda centers on the themes of equity, inclusion, student academic success, and student persistence for marginalized groups in higher education. Email: meallen1@ncat.edu

SANDRA L. DIKA, Ph.D., is an Associate Professor of Educational Research, Measurement, and Evaluation in the Department of Educational Leadership at UNC Charlotte. Her research agenda centers on the themes of equity, access, engagement, and persistence for marginalized and minoritized groups in higher education. Email: sdika@uncc.edu 